San Jose State University

SJSU ScholarWorks

Master's Theses

Master's Theses and Graduate Research

1996

\title{
The relationship of the work environment and job satisfaction of staff nurses
}

Cecilia Almazan-Cayabyab

San Jose State University

Follow this and additional works at: https://scholarworks.sjsu.edu/etd_theses

\section{Recommended Citation}

Almazan-Cayabyab, Cecilia, "The relationship of the work environment and job satisfaction of staff nurses" (1996). Master's Theses. 1209.

DOI: https://doi.org/10.31979/etd.9z6k-fh49

https://scholarworks.sjsu.edu/etd_theses/1209

This Thesis is brought to you for free and open access by the Master's Theses and Graduate Research at SJSU ScholarWorks. It has been accepted for inclusion in Master's Theses by an authorized administrator of SJSU ScholarWorks. For more information, please contact scholarworks@sjsu.edu. 


\section{INFORMATION TO USERS}

This manuscript has been reproduced from the microfilm master. UMI films the text directly from the original or copy submitted. Thus, some thesis and dissertation copies are in typewriter face, while others may be from any type of computer printer.

The quality of this reproduction is dependent upon the quality of the copy submitted. Broken or indistinct print, colored or poor quality illustrations and photographs, print bleedthrough, substandard margins, and improper alignment can adversely affect reproduction.

In the unlikely event that the author did not send UMI a complete manuscript and there are missing pages, these will be noted. Also, if unauthorized copyright material had to be removed, a note will indicate the deletion.

Oversize materials (e.g., maps, drawings, charts) are reproduced by sectioning the original, beginning at the upper left-hand corner and continuing from left to right in equal sections with small overlaps. Each original is also photographed in one exposure and is included in reduced form at the back of the book.

Photographs included in the original manuscript have been reproduced xerographically in this copy. Higher quality 6" $\times 9$ " black and white photographic prints are available for any photographs or illustrations appearing in this copy for an additional charge. Contact UMI directly to order.

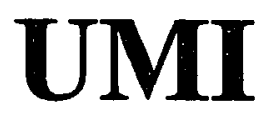

A Bell \& Howell Information Company 300 North Zeeb Road, Ann Arbor MI 48106-1346 USA 



\title{
THE RELATIONSHIP OF THE WORK ENVIRONMENT AND JOB SATISFACTION OF STAFF NURSES
}

\author{
A Thesis \\ Presented to \\ The Faculty of the school of Nursing \\ San Jose State University
}

\author{
In Partial Fulfillment \\ of the Requirements for the Degree \\ Master of Science
}

by

Cecilia Almazan-Cayabyab

May, 1996 
UMI Number: 1379324

\section{Copyright 1996 by \\ Almazan-Cayabyab, Cecilia \\ All rights reserved.}

UMI Microform 1379324

Copyright 1996, by UMI Company. All rights reserved.

This microform edition is protected against unauthorized copying under Title 17, United States Code.

\section{UMI}

300 North Zeeb Road

Ann Arbor, MI 48103 
(1) 1996

Cecilia Almazan-Cayabyab

ALL RIGHTS RESERVED 
APPROVED FOR THE SCHOOL OF NURSING

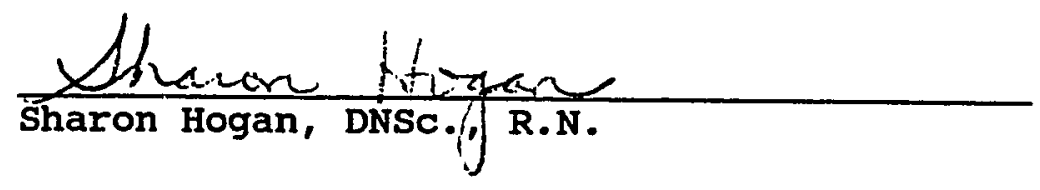

Legenene E.ppaloy

Suzarine Malloy, Ed.D.dR.N.

$\frac{\text { Debonh Summus-Caline }}{\text { Deborah summers-collins, M.S., M.P.H., R.N. }}$

APPROVED FOR THE UNIVERSTTY

M. Lou Aewandowach. 
ABSTRACT

THE RELATIONSHIP OF THE WORK ENVIRONMENT AND JOB SATISFACTION OF STAFF NURSES

by Cecilia Almazan-Cayabyab

Changes in the health care reimbursement system have created changes in the nurses' work environment as hospitals restructure to be more cost-effective. Restructuring of the work place can create job dissatisfaction among hospital staff nurses. This thesis explores the relationship between the work environment and job satisfaction of hospital staff nurses. Data were collected at a private Catholic hospital in Northern California, utilizing a nonexperimental, crosssectional survey design. Moos' (1994) Work Environment Scale and Whitley and Putzier's (1994) Work Quality Index (WQI) were used to collect data from nurses employed at the hospital $(\underline{\mathrm{N}}=52)$.

A statistically significant correlation was found between the perceived work environment and perceived job satisfaction of hospital staff nurses. The lack of involvement, peer cohesion, supervisor support, clarity, innovation, physical comfort, and perception of too much work pressure were attributed as factors that contribute to job dissatisfaction of hospital staff nurses. 
ACKNOWLEDGMENTS

To Sharon, Sue, and Debbie for their time, support, and expertise

To Coleen for her encouragement, and support

To Mom and Dad for instilling in me the value of education. Thank you for your love and support

To Cherry and Christy

for always understanding

To my grandma for always believing in me

To my husband, Ruben, without whom none of this would have been possible. Thank you for all the love, support, patience, understanding, and inspiration you have given me. 
TABLE OF CONTENTS

Page

LIST OF TABLES . . . . . . . . . . . . . . . . . . viii Chapter

1. INTRODUCTION . . . . . . . . . . . . 1

Background . . . . . . . . . . . . 1

Problem statement . . . . . . . . . . . 5

Research Question . . . . . . . . 6

Purpose . . . . . . . . . . . . 6

2. CONCEPTUAL FRAMEWORK AND REVIEW OF RELATED

LITERATURE • . • • . . . . . . . 7

Conceptual Framework . . . . . . . . . 7

Review of Literature . . . . . . . . . . 9

Summary . . . . . . . . . . . . . 15

3. METHODOLOGY . . . . . . . . . . . . 16

Research Design . . . . . . . . . 16

Setting and Sample . . . . . . . . . 16

Data Collection . . . . . . . . . . . 17

Measurement . . . . . . . . . . . 17

Data Analysis . . . . . . . . . . . 19

Scope and Limitations . . . . . . . . . 20

4. FINDINGS AND INTERPRETATION OF DATA . . . . . 21

Sample Characteristics . . . . . . . . 21

Work Environment . . . . . . . . . . . 23

Job Satisfaction . . . . . . . . . . . 27

vi 
Work Environment and Job Satisfaction . . . 31 Summary . • . • . . . . . . . . • 33

5. CONCLUSIONS AND RECOMMENDATIONS . . . . . . 35

Summary . . . . . . . . . . . . . 35

Conclusions . . . . . . . . . . . . 36

Recommendations . . . . . . . . . 37

REFERENCES . . . . . . . . . . . . . . . . 39

APPENDIXES
A. Cover Letter . . . . . . . . . . 43
B. Demographic Questionnaire . . . . . . 45
C. Work Environment Scale . . . . . . . 47
D. Work Quality Index . . . . . . . . 53
E. Permission Letter . . . . . . . . 56 


\section{LIST OF TABLES}

Table Page

1. Demographic Information . . . . . . . . . 22

2. Work Environment Scale Scores . . . . . . . . 24

3. Work Quality Index . . . . . . . . . . . 28

4. Work Environment and Job Satisfaction . . . . 32 
Chapter 1

INTRODUCTION

This study focuses on the relationship of the work environment and job satisfaction of nurses. The concept of job satisfaction of nurses has been studied extensively due to the nursing shortage of the 1980s; thus, concerns during that era were focused towards the retention of hospital nurses. Since the introduction of the prospective payment systems, numerous changes occurred in the work environment of nurses as hospitals were forced to be more costeffective. The nursing department accounts for a large portion of most hospitals' operating budget; thus, nursing productivity has become a critical issue. Nurses were expected to increase their productivity by delivering care more efficiently with fewer resources (Ketter, 1994a). As hospitals restructure, changes in the work environment may affect the job satisfaction of hospital nurses. The findings of this study should provide information to nursing administration on developing and promoting a work environment conducive to nurses, thereby increasing productivity, job satisfaction, retention, and the quality of patient care.

\section{Background}

The health care reform debate stimulated changes in the health care industry. Some hospitals are implementing costcontainment measures by merging, restructuring, or 
redesigning the workplace (Ketter, 1994a). Consolidation of hospital units, staff, and services is evident in hospitals undergoing restructuring in order to be more cost-effective (Ketter, 1994b). The nurse is expected to deliver more care with fewer resources without compromising quality of patient care.

In the 1980s, the prospective payment systems (PPS) were introduced to control escalating health care costs. Services were reimbursed on a fixed dollar amount based upon the case mix diagnosis of related groups (DRGs). Because PPS and third party payers limited the amount of money reimbursed for services provided and discouraged lengthy hospital stays, hospitals were forced to operate differently by assuming a business-like orientation (DiVestea, 1985). Hospitals found ways to cut down on costs to be financially secure.

In the 1990s, selective competition emerged as a way of containing health care costs. Health care providers, including hospitals, Preferred Provider organizations, and Health Maintenance organizations, competed for customers and services at a lower cost. According to Shindul-Rothschild (1994):

Under the new financing agreement, insurers were given unlimited discounts with hospitals. Government no longer negotiated with hospitals. Instead, the price for hospitals would be determined as providers 
competed against each other, offering discounts to managed care of health insurance providers. (p. 497)

Competition has now become the driving force in health care today, as hospitals restructure to increase their ability to underbid the competition (Shindul-Rothschild, 1994). Hospitals have attempted to increase their competitive ability by providing services more efficiently, decreasing hospital stays, and consolidating or eliminating services. Consequently, patients who are hospitalized usually have higher acuity levels than in the past and require a higher level of skilled care because of the amount of sophisticated technology involved in their care. As a result, considerable stress is placed on the nurse to complete tasks, finish paperwork, and provide patient and family teaching in the amount of time available. These changes in the work environment may affect job satisfaction of hospital nurses and thereby compromise quality patient care.

Studies have shown that there is a relationship between the work environment and job satisfaction of nurses. Mansfield, Yu, Mccool, Vicary, and Packard (1989) developed the Job Context Index. The Index serves as "a guide for improving the 'fit' between nurses and their work environment" (p. 501). According to Mansfield et al. (1989): The literature has suggested that the tension arising 
from a poor match between nurses and their workplace results often in burnout, dissatisfaction, and subsequent high levels of turnover. We believe that the Job Context Index, in conjunction with other preemployment evaluative tools, may enable nurse administrators to attain more stable and satisfying job placements. These strategies, together with adequate staffing and appropriate rewards, should result hopefully in better morale, lower stress, reduced turnover of staff, and increased savings for institution. (p. 507)

Kramer and Schmalenberg (1988b) studied the characteristics of magnet hospitals and compared their characteristics to those of the best-run corporations. The findings indicated that a quality health care environment leads nurses to work in these hospitals. The authors delineated some characteristics about magnet hospitals similar to those of the best-run corporate communities: They are infused with values of quality care, nurse autonomy, informal, nonrigid verbal communication, innovation, bringing out the best in each individual, value of education, respect and caring for the individual, and striving for excellence. They are led by nurse leaders and managers who are zealots in holding and promulgating these values. Many of the basic principles of the excellent companies are clearly 
present in the magnet hospitals. Though there is variability between the magnets, as there was between and among the excellent companies, perhaps the presence of so many of the basic principles in these hospitals is what has earned them the reputation of excellence in nursing practice. (p. 17)

An understanding of nurses' job satisfaction as it relates to their environment may benefit nurses and improve the delivery of quality care in hospitals. Since restructuring is currently the trend in hospitals, it is imperative to study nurses' work environment as it relates to job satisfaction, in order to help in future development of the nursing profession.

\section{Problem Statement}

The health care environment is currently undergoing considerable changes. Changes in the health care reimbursement system that resulted in hospital restructuring and redesigning of the nurses' work environment are areas that need to be studied, since considerable stress is placed on the nurse to adapt to the changing work environment. Attrition, burnout, and compromised patient care quality may result if a nurse continues to work in an environment that does not provide sufficient support. It is important for the health care institution to provide a work environment that increases nurses' productivity, job satisfaction, and retention. Therefore, this study seeks to focus on these issues. 


\section{Research Question}

The research question for this study is: Is there a relationship between the work environment and job satisfaction of nurses?

\section{Purpose}

The purpose of this study is to determine if there is a relationship between the work environment and job satisfaction of hospital staff nurses. However, the longterm goal of this study is to provide information to nursing administration in order to make necessary changes in the work environment to increase nurses' job satisfaction and thereby improve the quality of patient care. 


\section{Chapter 2}

CONCEPTUAL FRAMEWORK AND REVIEW OF IITERATURE

Moos (1994) used his "Conceptual Model of

Organizational and Personal Factors and outcomes" to guide the development of the Work Environment Scale (WES). Moos' (1994) model serves as the conceptual framework for this study. Moos offers a framework that encompasses three perspectives in the workplace: the human relations approach, the sociotechnical perspective, and social information processing. The human relations perspective emphasizes the quality of relationships among employees and management. The sociotechnical perspective reflects the idea that work stressors of employees arise from the nature of tasks performed and how work groups are organized. Finally, social information processing is an appraisal of the work situation by employees. The model examines job-related and personal factors that influence outcomes in the work environment. The model also implies that the work stressors which employees face stem from the environment, as well as from the interactions of people outside their work environment.

Panel 1 (Organizational system), is composed of physical features, organizational structure, and policies, suprapersonal and work task factors, and work climate. Panel II (Personal Factors) contains characteristics of individual employees, such as job position and level of experience, sociodemographic background, personal resources such as 
self-confidence, and their expectations and preferences about the workplace. The conceptual model shows that Panel III (Work stressors) is an outcome between the interplay of Panel I and Panel II. The organizational system (Panel I), personal factors (Panel II), and work stressors (Panel III), can shape coping responses (Panel IV), as well as work morale and performance (Panel v). In turn, work morale and performance affect organizational outcomes, such as quality of service and client and student outcomes (Panel VI). Analysis of the model shows that individuals choose coping responses brought about by environmental and personal systems in order to regulate their work environment. The coping responses of the employees affect the work morale, performance, quality services, and client outcomes. These outcomes translate to quality of care in health care settings. "Finally, as the bidirectional paths in the model indicate, these processes are transactional; feedback can occur at each stage" (Moos, 1994, p. 28).

The framework relies on an understanding of the perspective of the social climate. According to Moos (1976), "The social climate perspective assumes that environments, like people, have unique 'personalities.' Social environments can be portrayed with a great deal of accuracy and detail" (p. 320). Moos developed the Work Environment Scale (WES), the tool used to measure the work environment, using three domains of the social climate. The first domain 
contains relationship dimensions. The first domain examines the extent of individual involvement in the environment. It includes the subscales of involvement, cohesiveness, and support. The second domain, identified as "personal growth", contains subscales of autonomy, task orientation, and work pressure. The last domain, that of "systems maintenance change", includes basic dimensions such as organizational factors of clarity, control, innovation, and physical comfort.

Moos' conceptual framework has been used extensively to investigate work climate concerns in a variety of settings, including those of health care agencies. The following section discusses several of these pertinent studies.

\section{Review of Literature}

Many hospitals are instituting cost-containment measures by restructuring or redesigning the workplace. Restructuring of the health care delivery system creates changes in the work environment for nurses as hospitals change the way they operate and the way employees are utilized. According to Ketter (1994a), "Restructuring in hospitals often means changing workloads and/or assignments, cross-training, lowering labor costs, consolidating or eliminating services, and using case management" (p. 1). Restructuring may also result in lower staffing and reduced numbers of registered nurses in direct patient care. Today, restructuring is the trend in hospitals nationwide as they 
attempt to reduce costs while maintaining quality patient care.

Moos (1994) developed the "Work Environment Scale" (WES) to measure the work environment in a variety of settings. The WES was constructed as a result of Moos' extensive studies about the social climate of work groups. The WES "has been used extensively to describe and analyze the work environment in various settings" (Flarey, 1993, p. 9). Several studies in the health care setting used the WES to monitor changes, such as reorganizing hospital nursing services, conducting self-evaluations of the workplace, and evaluating organizational change (Moos, $1994)$.

Turnipseed (1990) utilized the WES to evaluate differences of the work environment among three shifts in a small rural hospital. To augment the study, the surveyed nurses were also personally interviewed. The study found that each shift had different work climates. The study concluded that the organizational climate must be measured on different shifts and units. The WES was also used to describe and reduce work stressors among staff nurses in an ICU unit. The study found that job dissatisfaction was caused by high work demands, role ambiguity, lack of autonomy, and inadequate supervisor support (Koran, L., Moos, R., Moos, B., Zasslow, M., 1983). It was evident from both studies that the WES had been beneficial in 
identifying problems in the work environment.

Factors in the work environment may influence job satisfaction of nurses. A study of magnet hospitals by Kramer and Schmalenberg (1988a) delineated factors in the hospital work environment that were perceived as satisfying to nurses. The study looked at 16 magnet hospitals and analyzed what characteristics they possessed that were similar to the best-run companies in the corporate community. Each hospital was visited and studied for a period of 2 to 6 days. Hospital units were visited during all three shifts. More than 800 staff nurses and 247 head nurses and clinical specialists were interviewed. The authors found that the nurses in the magnet hospitals consider their hospital a good place to work. The characteristics that made the hospitals a good place to work were similar to those of the best-run corporate communities. Some of the identified characteristics were: values of quality patient care, nurse autonomy, nonrigid verbal communication, and bringing out the best in each individual (Kramer \& Schmalenberg, 1988b).

Kramer and Schmalenberg (1991a), building on their previous research on magnet hospitals, probed further by conducting a study to find out what makes magnet hospitals a good place to work. The study compared the work environment and job satisfaction of nurses from magnet and nonmagnet hospitals. The first group consisted of nurses from 14 of 
the 16 magnet hospitals from their earlier study. The second group of nurses was drawn from Nursing 89 subscribers across the United States. There were 939 magnet hospital nurses and 808 nonmagnet hospital nurses who responded to the survey. The research findings indicated the "importance of a hospital's culture in satisfying nurses and giving them a sense of professional fulfillment" (Kramer \& Schmalenberg, 1991b, p. 51). The magnet hospitals nurtured a culture of excellence that included involving the nurses in decision-making, allowing nurses to function autonomously, and having nurse leaders who are supportive of staff nurses. The authors also found several variables that increased job satisfaction of nurses. These variables were: organizational structure (staffing, salary, etc.), professional practice (relationship with doctors and other professionals, etc.), management style (quality of leadership), and professional development. The results of this study are similar to an earlier study conducted by Wandelt, Pierce, and widowson (1981) .

Wandelt et al., in response to the nursing shortage, conducted a study to find out what makes nurses leave or stay in their profession (1981). Thirty-five hundred employed and nonemployed nurses responded to the study by filling out a questionnaire. In addition, 30 hospital nurses were interviewed to augment those data. Results from the quantitative questionnaire study were similar to the results gathered from the qualitative interview data. Findings 
suggest that job dissatisfaction is related to the work environment rather than the nursing profession itself. The characteristics of the work environment related to job dissatisfaction included lack of support given by the administration, lack of autonomy, and an environment that does not provide a sense of self-worth.

Several studies have shown that the work environment affects job satisfaction of nurses (Kramer \& Schmalenberg, 1991a; Kramer \& Schmalenberg, 1991b; Wandelt et al., 1981). Job satisfaction of nurses is one of the factors that keeps nurses in nursing. Retention of nurses may mean better quality care for patients and increased savings to acute care hospitals because nursing administration would not have to spend as much money orienting new nurses.

Some studies have looked at the relationship of the work environment and job satisfaction of nurses (Tumulty, Jernigan, \& Kohut, 1994; Turnipseed, 1990). Tumulty et al. investigated the effects of the work environment on job satisfaction of nurses (1994). The study surveyed nurses in two acute care facilities. The response rate was $40 \%(\underline{\mathbb{N}}=$ 159). The authors found that relationships in the health care setting are important. "Because the nurses were essentially dissatisfied with their jobs, they may focus on the components of the job, over which they have greater control, such as their relationships with the peers, colleagues, and patients" (Tumulty et al., 1994, p. 89). 
Other studies have suggested various components or factors in a work environment that affect nurses' job satisfaction. Some studies suggested that supportive nursing management may be a source of job satisfaction of nurses (Kramer \& Schmalenberg, 1991a; Nakata \& Saylor, 1994 ; Wandelt et al., 1981). Nakata and Saylor (1994) surveyed nurses in an acute care hospital to find if there was a relationship between perceived management styles and job satisfaction of nurses. The sample consisted of 239 registered and licensed vocational nurses; 102 nurses responded to the questionnaire. Findings of the study indicated that a participative management style increased job satisfaction of nurses. A participative management style includes autonomy, good communication, control that is shared by all members, and decisions that are made at all levels. The study suggested that a management style that is preferred by nurses, and one which considers nurses' job satisfaction, may result in improved patient outcomes. The results of Nakata and Saylor's (1994) study supported Blegen's (1993) meta-analysis of 48 studies that examined what variables were commonly associated with job satisfaction of nurses. Results of the meta-analysis indicated that autonomy, communication with supervisor, peer fairness, and locus of control were variables that were commonly associated with job satisfaction. 
Summary

A review of literature reveals that the work environment may be a major factor in job dissatisfaction among hospital nurses. Researchers agree that there are several factors in the work environment that increase job satisfaction of nurses and, therefore, improve quality of patient care. Creating a work environment that promotes satisfaction of nurses increases nursing productivity and retention of nurses, translating into increased savings for hospitals. 


\section{Chapter 3}

\section{METHODOLOGY}

Research Design

This study used a nonexperimental, cross-sectional design to investigate the relationship between perceived work environment and perceived job satisfaction of hospital staff nurses. The independent variable was perceived work environment, and the dependent variable was perceived job satisfaction. Cross-sectional design involves the collection of data from different subjects in one single time frame. This design allows the researcher to collect ample data economically in a short period of time. However, in using this design, a detailed analysis of the interrelationships among the phenomena being studied cannot be determined (Massey, 1995).

\section{Setting and Sample}

The setting was a 222-bed general, acute care, private, nonprofit Catholic hospital located in Northern California. The hospital offers medical, surgical, pediatrics and maternal-child care, 24-hour emergency services, cardiac catheterization, and outpatient services. The population served includes those on federal or state assistance and private payers.

The sample consisted of 110 registered and licensed vocational nurses. All regularly scheduled full-time and part-time staff nurses who provided bedside patient care in 
the medical, surgical, and transitional care units were included. Nurses who hold managerial positions were not included in the sample.

\section{Data collection}

The Vice President of Patient Care Services gave permission to use the agency. The questionnaire was attached to the nurse's time card. The questionnaire packet included a cover letter explaining the purpose of the study and a self-addressed, stamped envelope for return of the completed questionnaire to the researcher (see Appendix A). Anonymity of the completed survey was assured because there was no way to identify the individual who filled out the survey. A flyer about the study was posted in the nurses' lounge encouraging nurses to participate. The completed surveys were returned to the researcher's home in a postage paid envelope. The completed surveys were kept in a locked box in the researcher's home until the conclusion of the study, when they were destroyed.

\section{Measurement}

A demographic questionnaire (see Appendix B) was included in the survey. It included gender, age range, educational level, work status, shift worked, years of employment, and floor worked. The work environment (independent variable) was measured using the Work Environment Scale (WES) developed by Moos (see Appendix C). The WES has three forms, but only Form $R$ was utilized. 
Form $R$ measures the perceptions of the managers and employees of their current work environment. This form can be used to evaluate climates in the work environment, identify individual perceptions of the person's work environment, and promote improvement (Moos, 1994). The scale has 90 items in a true/false format, divided into 10 individual subscales which measure involvement, peer cohesion, supervisor support, autonomy, task orientation, work pressure, clarity, control, innovation, and physical comfort. The 10 subscales are organized into the following three dimensions: Relationship, Personal Growth and Orientation, and system Maintenance Change.

The Relationship Dimension measures how employees are concerned and committed to their jobs (involvement), how friendly and supportive the employees are to each other (peer cohesion), and how supportive the management is to employees (supervisor support). The Personal Growth or Goal Orientation Dimension measures to what extent employees are independent (autonomy), how much emphasis is put on getting the job done (task orientation), and job demands (work pressure). The system Maintenance and System Change Dimension measures the work setting's emphasis on rules and policies (clarity); how management uses rules and pressures to keep employees under control (control); the degree of emphasis on variety, change, and new approaches (innovation); and the pleasantness of the physical setting 
(physical comfort).

Moos' (1994) WES instrument was tested for validity by sampling a total of 624 employees and managers in 44 work groups "to ensure that the WES would apply in a variety of settings" (p. 20). Moos (1994) reported that the test-retest reliabilities in a 1-month interval between test administrations ranged from .69 to .83 .

Job Satisfaction (dependent variable) was measured using Whitley and Putzier's (1994) Work Quality Index (WQI) (see Appendix D). The scale has 38 items in a Likert scale format divided into 6 subscales: work environment, autonomy, work worth, relationships, role enactment, and benefits. The questionnaire has response choices from 1 to 7 , and the respondent is asked to circle the appropriate number closest to respondent's feelings.

The validity of the WQI was tested by sampling 245 RNs at a large acute care medical center. Construct validity was established through factor analysis. Reliability of the instrument was tested using Cronbach's Alpha test for homogeneity. The Cronbach's alpha reliability was reported from .72 to .94 . Respondents were informed that together the WES and WQI questionnaires take about 20 minutes to complete.

\section{Data Analysis}

Data were analyzed using descriptive statistics, including frequencies, percentages, means, and standard 
deviations. The work environment scores were compared to normed average ranges. A Pearson product-moment correlation was used to analyze the relationship between the work Environment Scale and the Work Quality Index score.

\section{Scope and Limitations}

The study was limited by design, sample, and data collection method. Because the design was cross-sectional, a cause and effect relationship could not be determined. The sample came from one hospital; thus, it may not be a representative sample of all staff nurses. Also, the nurses who responded to the questionnaire might be different in some way from the nurses who did not respond. Therefore, the results of the study can only be generalized to a population similar to that of the study. 


\section{Chapter 4 \\ FINDINGS AND INTERPRETATION OF DATA}

The purpose of this study was to determine if there was a relationship between the perceived work environment and perceived job satisfaction of hospital staff nurses. The long-term goal of this study is to provide information to the nursing administration about components of the work environment that are satisfying to nurses. The perceived work environment was measured by analyzing the data collected from the Work Environment Scale (WES). The perceived job satisfaction of hospital staff nurses was analyzed using the data collected from the work quality Index (WQI). Demographic data were also collected and analyzed.

\section{Sample Characteristics}

There were 57 (51.8\%) questionnaires returned from the 110 questionnaires distributed. However, only 52 (47.2\%) questionnaires were usable for this study. The results of the demographic questionnaire are summarized in Table 1.

The demographic data revealed that the sample was composed of 2 men and 50 women. The respondents had a mean age group of 40-44 years of age. The respondents had been employed at the hospital a range of 1 year to 30 years. The majority of the nurses reported working in the Medical/ Surgical area. There were $19.2 \%(\underline{n}=10)$ nurses who reported 
Table 1

Demographic Information (N $=52)$

Frequencies

\%

Gender

Male

Female

2
50

3.8

96.2

License

RN

LVN
47

5

Degree Held

Diploma

BSN

AA

Master's

Hours Worked

Full-time

Part-time

Shift Worked

Days

Evenings

Nights

Unit Worked
10

27

14

1

30

22

22

20

10

10

5

23

14
90.4

9.6

19.2

52.0

26.9

1.9

57.7

42.3

42.3

38.5

19.2

19.2

9.6

44.2

27.0 
working on 3rd floor, $9.6 \%(\underline{n}=5)$ working on 4th floor, and $44.2 \%(\underline{n}=23)$ working on 5 th floor. Fourteen of the nurses (27\%) reported working on the Transitional Care Unit. Forty seven $(90.4 \%)$ respondents were registered nurses, while 5 (9.6\%) were licensed vocational nurses. Data collected revealed that the majority of the nurses $(\underline{n}=27$, 52\%) have earned Bachelor's degrees (BSN). The other nurses in the sample had Associate degrees $(\underline{n}=14,26.9 \%)$, diploma $(\underline{n}=10,19.2 \%)$, and Master's degrees $(\underline{n}=1,1.9 \%)$. The majority of the respondents held full-time $(\underline{n}=30,57.7 \%$ ) positions, while the minority held part-time positions ( $\underline{n}=$ $22,42.3 \%)$. Twenty-two $(42.3 \%)$ respondents work during the day, $20(38.5 \%)$ respondents work during the evening, and 10 (19.2\%) respondents work during the night. Among the respondents, only 2 (3.8\%) were anticipating leaving the hospital.

\section{Work Environment}

The Work Environment Scale has 90 items in a true/false format, divided into 10 individual subscales: involvement, peer cohesion, supervisor support, autonomy, task orientation, work pressure, clarity, control, innovation, and physical comfort. The mean and standard deviation were determined for each subscale, as depicted in Table 2.

The findings revealed that the involvement subscale had a mean of 4.25 , which was well below the normed average mean of 5.43 for health care workers. Involvement measures to 
Table 2

Work Environment Scale Scores $(N=52)$

\begin{tabular}{llll}
\hline Subscales & Mean & SD & Normed Mean \\
\hline Involvement & 4.25 & 2.18 & 5.43 \\
Peer Cohesion & 4.56 & 2.03 & 5.24 \\
Supervisor Support & 2.85 & 2.04 & 4.82 \\
Autonomy & 4.41 & 1.61 & 5.20 \\
Task orientation & 6.75 & 1.52 & 5.70 \\
Work Pressure & 8.20 & 1.30 & 5.65 \\
Clarity & 3.27 & 1.82 & 4.50 \\
Control & 7.31 & 1.21 & 5.57 \\
Innovation & 4.14 & 1.80 & 3.90 \\
Physical Comfort & 2.19 & 2.10 & 3.77 \\
\hline
\end{tabular}


what extent employees are concerned and committed about their jobs. The peer cohesion subscale had a mean of 4.56 (well below the normed average of 5.24 ). Peer cohesion measures to what extent employees are supportive and friendly of one another. The staff nurses responded to the supervisor support subscale with a mean of 2.85 (considerably below the normed average of 4.82). Supervisor support assesses the extent to which management is supportive of employees. The autonomy subscale had a mean of 4.41 (well below the normed average of 5.20). Autonomy measures the extent to which employees are encouraged to make their own decisions and to be self-sufficient. The task orientation subscale had a mean of 6.75 (well above the normed average of 5.70). Task orientation measures the degree of emphasis on good planning, efficiency, and getting the job done.

Under the work pressure subscale, the mean was 8.20 (considerably above the normed average of 5.65). Work pressure measures the extent to which the pressure of work and time urgency dominate the job milieu. The clarity subscale had a mean of 3.27 (considerably below the normed average of 4.50 ). Clarity assesses the extent to which employees know what to expect in their daily routine and how rules and policies are communicated. The control subscale was scored with a mean of 7.31 (considerably above the normed average of 5.57). Control measures the degree to 
which management uses rules and pressures to keep employees under control.

The staff nurses responded to the innovation subscale with a mean of 4.14 (well below the normed average of 3.90). Innovation measures the degree of emphasis in variety, change, and new approaches. The physical comfort subscale was given a mean of 2.19 (considerably below the normed average of 3.77 ). Physical comfort measures the degree to which the physical surroundings contribute to a pleasant work environment.

Analysis of the data from the Work Environment Scale revealed that the respondents rated task orientation, work pressure, and control as above average and higher than the normed mean. Supervisor support and physical comfort were rated considerably below average and below the normed mean. This may reflect the perceived difficulty of the work and stressful environment that nurses' encounter in the acute health care setting. Agencies and employers place considerable emphasis on nurses to finish tasks and patient care on time. Because of the changes in the health care reimbursement system, acute care nurses are expected to deliver patient care more efficiently while containing costs. Additionally, nurses are expected to follow established policies and procedures while doing their work. Koran et al. (1983), utilizing Moos' WES instrument, found that job dissatisfaction was caused by high work demands, 
role ambiguity, lack of autonomy, and inadequate supervisor support. These data also revealed that the respondents perceived a lack of supervisor support and physical comfort. The studies of Kramer and Schmalenberg (1991b) and Wandelt et al. (1981) revealed that a lack of supervisor support often results in dissatisfaction among hospital nurses.

\section{Job Satisfaction}

The perceived job satisfaction of staff nurses was analyzed using the Work Quality Index (WQI) developed by Whitley and Putzier (1994). The scale has 38 items, in a Likert scale format, divided into 6 subscales: work environment, autonomy, work worth, relationship, role enactment, and benefits. The questionnaire has response choices from 1 to 7 . Results of the WQI questionnaire are presented in Table 3.

The WQI subscale with the highest mean was the subscale of work worth to self and others (5.20). The work worth subscale shows that nurses value work contributions that are personally interesting and contribute to their own selfworth (Whitley \& Putzier, 1994). The ability to make contributions to the hospital, profession, personal sense of achievement, and the opportunity to use a full range of skills were items assessed in the WQI survey. In this study, the subscale which scored the lowest mean was the professional work environment subscale (3.77). The items in the professional work environment subscale represent the 
Table 3

Work Quality Index $(N=52)$

\begin{tabular}{llll}
\hline Subscales & Mean & SD & Range \\
\hline $\begin{array}{l}\text { Professional work } \\
\text { Environment }\end{array}$ & 3.77 & 1.55 & $1.0-7.0$ \\
Autonomy & 4.82 & 1.33 & $1.0-7.0$ \\
Work Worth & 5.20 & 1.40 & $1.0-7.0$ \\
Professional & 4.17 & 1.59 & $1.0-7.0$ \\
Relationships & & & $1.0-7.0$ \\
Professional & 4.02 & 1.43 & $1.0-7.0$ \\
Role Enactment & 4.32 & 1.60 & $1.0-7.0$ \\
Benefits & 4.34 & 1.48 & \\
Overall Mean & & & \\
\hline
\end{tabular}


nurses' need to have a voice in the way their work environment is contrived. It is also a reflection of nurses' need for professional growth and support for their work from nursing service hierarchies (Whitley \& Putzier, 1994). Some of the items included in the subscale were: voice in policy making for nursing service, hospital policy making, opportunity for professional growth, respect from nurses on other units, praise from nursing administration, and an organizational structure that supports patient care.

The mean score for the subscale of autonomy (S.D.= 1.33) was 4.82 . The items that were included in the autonomy subscale underscore the fact that nurses enjoy as much autonomy as possible in their roles (Whitley \& Putzier, 1994). The professional role enactment had a mean score of 4.02. The professional role enactment included items such as nurses finding their work satisfying when they are faced with a variety of challenges, as well as the ability to complete required tasks on time (Whitley \& Putzier, 1994). The professional relationships subscale scores resulted in a mean of 4.17. According to Whitley and Putzier (1994), nurses continually demonstrate the need to work with nurses and physicians who support their work and whom they are able to form professional relationships. The subscale of benefits had a mean score of 4.32 . Some of the items that were included in the benefits subscale were: satisfactory salary, financial benefits, adequate sick leave, and job 
advancement.

As mentioned earlier, the subscale with the highest mean was work worth, and the subscale with the lowest mean was the professional work environment. These results indicated that the nurses surveyed felt that they were making contributions to the hospital, their profession, and that they had a personal sense of achievement. The results also indicated that they found least satisfaction in their professional work environment. This means that they were not involved in decision making in their hospital and on the units where they work. They also felt that they were not getting support and respect from nursing administration and from nurses on other units.

The overall work quality index mean was 4.34 , from a possible scale of 1 to 7. Kramer and Schmalenberg (1991b) found in their study that magnet hospitals nurtured a culture of excellence that included nurses in decision making, allowed nurses to be autonomous, and is an environment which has nurse leaders who are supportive of staff members. The study of Wandelt et al. (1981) also found characteristics of the work environment that were related to job dissatisfaction of nurses. Those characteristics identified included lack of support given by the administration, lack of autonomy, and an environment that does not provide a sense of self-worth (Wandelt et al., 1981). 


\section{Work Environment and Job Satisfaction}

The relationship between the perceived work environment and perceived job satisfaction of hospital staff nurses was examined by utilizing the Pearson Product-Moment Correlation. The relationship of the subscales of the work environment scale and job satisfaction of hospital staff nurses was determined as shown in Table 4. An alpha level of .05 was used for all statistical tests. There was a significant relationship between involvement $(p=.000)$, peer cohesion $(\underline{p}=.004)$, supervisor support $(\underline{p}=.000)$, work pressure $(\underline{p}=.001)$, clarity $(\underline{p}=.000)$, innovation $(\underline{p}=.044)$, physical comfort $(\underline{p}=.002)$, and job satisfaction of hospital staff nurses. There was no significant relationship found between autonomy ( $p=.247$ ), task orientation $(\underline{p}=.080)$, and job satisfaction of hospital staff nurses.

As revealed by the review of literature, the work environment may be the cause of job dissatisfaction among hospital nurses. Lack of involvement, peer cohesion, supervisor support, clarity, innovation, physical comfort, and high work pressure all contribute to job dissatisfaction of hospital staff nurses. Although several previously mentioned studies have emphasized the importance of autonomy in determining job satisfaction of nurses, results indicate autonomy was not a significant factor in this study. 
Table 4

Work Environment and Job Satisfaction (N=52)

p

Job Satisfaction

Involvement

.000

Job Satisfaction

Peer Cohesion

.004

Job Satisfaction

Supervisor support

.000

Job Satisfaction

Autonomy

.247

Job Satisfaction

Task orientation

.080

Job Satisfaction

Work Pressure

.001

Job Satisfaction

clarity

.000

Job Satisfaction

Control

.852

Job Satisfaction

Innovation

.044

Job Satisfaction

Physical Comfort 


\section{Summary}

The analysis of the data collected in this study found that these surveyed staff nurses are experiencing lack of involvement, peer cohesion, supervisor support, autonomy, clarity, innovation, and physical comfort in their work environment. The nursing administration is not perceived as being supportive of staff nurses, and the staff nurses indicated they were not involved in decision making in their units. Also, results indicated that the physical surroundings of the units do not contribute to a pleasant work environment. Physical surroundings include factors such as good lighting, modern and stylish appearance of the place, and whether the colors and decorations make the place warm and cheerful to work in (Moos, 1994).

Analysis of the Work Quality Index questionnaire revealed that the staff nurses surveyed felt their work was making contributions to the hospital, their profession, and their personal sense of achievement. According to the literature, it has been understood that all who work want to spend their energies in endeavors that make a contribution (Whitley \& Putzier, 1994). However, the nurses surveyed felt that they were not involved in policy making for nursing services, and they were not receiving adequate praise for their job well done from the nursing administration.

The analysis of the perceived work environment and perceived job satisfaction of hospital staff nurses revealed 
a statistically significant correlation. A relationship was found between the work environment (involvement, peer cohesion, supervisor support, work pressure, clarity, innovation, and physical comfort) and job satisfaction of hospital staff nurses. The lack of involvement, peer cohesion, supervisor support, clarity, innovation, physical comfort, and excessive work pressure may all contribute to job dissatisfaction of hospital staff nurses surveyed in this study. 


\section{Chapter 5 \\ CONCLUSIONS AND RECOMMENDATIONS}

Summary

The purpose of this study was to determine if there was a relationship between the work environment and job satisfaction of hospital staff nurses. This study also explored factors in the work environment that may cause job dissatisfaction among hospital staff nurses. The findings of this study may assist nursing administration to promote factors in the work environment that increase nurses' job satisfaction and thereby increase nursing productivity, retention, and quality patient care.

The perceived work environment was measured utilizing Moos' (1994) Work Environment Scale, and the perceived job satisfaction was measured utilizing Whitley and Putzier's (1994) Work Quality Index scale. This study answered the following question: Is there a relationship between the work environment and job satisfaction of nurses?

The findings of this study have shown that there were factors in the work environment that may be causing job dissatisfaction among a group of Northern California hospital staff nurses. The staff nurses were experiencing increased work pressure, and supervisor support was perceived as somewhat lacking. They also felt that their professional work environment was a source of job 
dissatisfaction. However, the staff nurses felt that their work was making contributions to their own professional sense of achievement.

\section{Conclusions}

This study was conducted in recognition that staff nurses have been affected by hospital restructuring. As a result of changes in health care reimbursement, hospital institutions have been forced to be more cost-effective, while increasing their productivity.

Restructuring has affected nurses caring for patients at the bedside as their work environment has also been redesigned. Nurses are expected to deliver efficient care to patients with higher acuity levels while containing costs and downsizing staff. Nurses are also expected to supervise less trained personnel, like Licensed Vocational Nurses. Hence, considerable stress is placed on the nurse to deliver quality patient care while attempting to finish tasks efficiently. Based on many of these factors, job dissatisfaction among hospital staff nurses results. Job dissatisfaction can cause attrition and burnout, thereby decreasing nursing productivity - Compromised patient care quality may also result if the nurse continues to work in an environment that does not provide any support.

Job satisfaction among hospital nurses translates to increased savings to hospitals because satisfied nurses are apt to be more productive. Job satisfaction also reduces 
burnout, turnover rates, and absenteeism.

The findings of this study also suggested that there are factors in the work environment that may cause job dissatisfaction among hospital nurses. Increased work pressure is a source of job dissatisfaction among hospital nurses. Due to the nature of hospital work settings, increased work pressure is to be expected. However, a more supportive nursing management may compensate for this. The nurses surveyed felt that there was a lack of physical comfort in their work environment. Physical comfort includes factors such as good lighting and whether the colors and decorations make the place warm and cheerful to work in.

\section{Recommendations}

This study should be replicated using a larger sample size in a different geographic location and different settings. Further studies are needed to delineate factors in the work environment that are satisfying to nurses. It is also recommended to use not only Form $R$ of Moos' (1994) Work Environment Scale, but Form I should also be utilized, as well, to identify real and ideal perceptions of the work environment. These studies can provide information to nursing administration about factors in the work environment that are satisfying to nurses. Further studies are also needed to investigate the relationship between the work environment and job satisfaction of nurses in different types of nursing units. The results of the study in 
different nursing units should be compared to determine what factors seem to increase nursing satisfaction.

Based on the findings of this study, it is recommended that hospitals and the nursing administration create an environment that is satisfying to nurses if quality patient care is to be expected. The findings in this study indicate that there is a lack of support from supervisors, and the physical surroundings do not contribute to a good working environment. The nurses need to be involved in policy making in their units, and the nursing administration needs to support the work of the staff nurses. Physical surroundings can be promoted by involving the staff in decision making regarding how the units should be arranged and decorated. The significant relationship found between several factors in the work environment and job satisfaction among hospital staff nurses indicated the importance of a work environment that promotes job satisfaction of hospital staff nurses. 
REFERENCES 
References

Blegen, M. A. (1993). Nurses' job satisfaction: A metaanalysis of related variables. Nursing Research, $42,36-41$. DiVestea, N. (1985). The changing health care system: An overview. In F. A. Shaffer (Ed.), costing out nursing: Pricing our product (pp. 29-36). New York, NY: National League for Nursing.

Flarey, D. L. (1993). The social climate of work environments. Journal of Nursing Administration, 23, 9-15. Ketter, J. (1994a, May). ANA: Protecting nurses and patient care in the face of restructuring. The American Nurse, pp. 11-4.

Ketter, J. (1994b, July-August). RNs and restructuring: An overview. The American Nurse, pp. 1-22.

Koran, L., Moos, R., Moos, B., \& Zasslow, M. (1983). Changing hospital work environments: An example of a burn unit. General Hospital Psychiatry, 5, 7-13.

Kramer, M., \& Schmalenberg, C. (1988a). Magnet hospitals: Part I Institutions of excellence. Journal of Nursing Administration, $18(1), 13-24$.

Kramer, M., \& Schmalenberg, C. (1988b) . Magnet hospitals: Part II Institutions of excellence. Journal of Nursing Administration, $18(2), 11-19$.

Kramer, M. \& Schmalenberg, C. (1991a). Job satisfaction and retention: Insights for the '90s. Part I. Nursing $91,21,50-55$. 
Kramer, M., \& Schmalenberg, C. (1991b). Job satisfaction and retention: Insights for the '90s. Part II. Nursing $91,22,51-55$.

Mansfield, P. K., Yu, L. C., McCool, W., Vicary, J. R., \& Packard, J. S. (1989). The job context index: A guide for improving the 'fit' between nurses and their work environment. Journal of Advanced Nursing, 14, 501-508.

Massey, V. H. (1995). Nursing research (2nd ed.). Springhouse, PA: Springhouse.

Moos, R. (1976). The human context: Environmental determinants of behavior. New York, NY: John wiley \& Sons. Moos, R. (1994). Work environment scale manual (3rd ed). Palo Alto, CA: Consulting Psychologist's Press. Nakata, J. A., \& Saylor, C. (1994). Management style and staff nurse satisfaction in a changing environment. Nursing Administration Quarterly, 18, 51-57.

Shindul-Rothschild, J. (1994) . Restructuring, design, rationing, and nurses' morale: A qualitative study on the impact of competitive financing. Journal of Emergency Nursing, $20(6), 497-504$.

Tumulty, G., Jernigan, I. E., \& Kohut, G. F. (1994). The impact of perceived work environment on job satisfaction of hospital staff nurses. Applied Nursing Research, 7 , 84-90.

Turnipseed, D. (1990) . Evaluation of health-care work environments via a social climate scale: Results of a field 
study. Hospital Health Services Administration, 35, 245-262. Wandelt, M. A., Pierce, P. M., \& Widowson, R. R. (1981). Why nurses leave nursing and what can be done about it. American Journal of Nursing, $1,72-77$.

Whitley, M. P., \& Putzier, D. J. (1994). Measuring nurses' satisfaction with the quality of their work and work environment. Journal of Nursing Care Quality, 8, 43-48. 
APPENDIX A

Cover Letter 
I am Cecilia Cayabyab, a graduate student at San Jose State, and staff nurse at 5 th floor. I am conducting a study to find out if there is a relationship between the work environment and job satisfaction of nurses. This study has been approved by the vice President of Patient care Services and the Institutional Review Board at San Jose state University.

Enclosed is a packet of materials, including a demographic questionnaire, Work Environment Scale, and Work Quality Index. Should you choose to participate, you will be making a contribution to nursing because the findings of this study will give information to nursing administration on developing and promoting a work environment that is satisfying to nurses. Please fill out the attached questionnaire and mail it with the enclosed postage-paid envelope by November 17, 1995. Your response will be kept anonymous, and only Cecilia will have access to it. Results will be reported as a group data. The completed questionnaires will be destroyed at the conclusion of the study.

The findings of the study will be available to all participants at the end of the study. Thank you so much for your participation, and for making a difference. 
APPENDIX B

Demographic Questionnaire 
Demographic Questionnaire

1. Gender

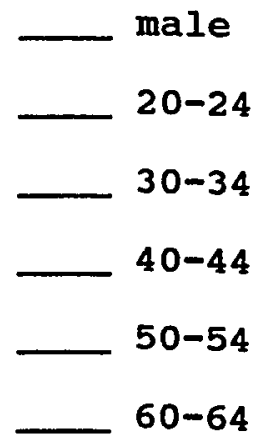

female

2. Age

3. Currently licensed as a:

_ Registered Nurse

Vocational Nurse

4. Highest level of nursing education completed

Diploma Program $\quad$ Associate Degree
Baccalaureate Program _ Master's
Other

5. How much do you work?
_ Full-time
$4 / 5$
$3 / 5$
$2 / 5$
Per diem/extra

6. What is your shift?

Days __ Evenings _ Nights

7. Years of employment?

years

8. What floor do you work in?

- $3 \mathrm{rd}-4 \mathrm{th} \longrightarrow 5 \mathrm{th}-\mathrm{TCU1} \longrightarrow \operatorname{TCU} 4$

9. Are you currently anticipating leaving the hospital?

Yes _ No 
APPENDIX $\mathrm{C}$

Work Environment scale

Form $\mathbf{R}$ 


\section{Instructions}

There are 90 statements in this booklet. They are statements about the place in which you work. The statements are intended to apply to all work environments. However, some words may not be quite suitable for your work environment. For example, the term supervisor is meant to refer to the boss, manager, department head, or the person or persons to whom an employee reports.

You are to decide which statements are true of your work environment and which are false. Make all of your marks on the separate answer sheet.

If you think the statement is true or mostly true of your work environment, make an $\mathrm{X}$ in the box labeled $T$ (true).

If you think the statement is false or mostly false of your work environment, make an $x$ in the box labeled $F$ (false).

1. The work is really challenging.

2. People go out of their way to help a new employee feel comfortable.

3. Supervisors tend to talk down to employees.

4. Few employees have any important responsibilities.

5. People pay a lot of attention to getting work done.

6. There is constant pressure to keep working.

7. Things are sometimes pretty disorganized.

8. There's a strict emphasis on following policies and regulations.

9. Doing things in a different way is valued.

10. It sometimes gets too hot.

11. There's not much group spirit.

12. The atmosphere is somewhat impersonal.

13. Supervisors usually compliment an employee who does something well. 
14. Employees have a great deal of freedom to do as they like.

15. There's a lot of time wasted because of inefficiencies.

16. There always seems to be an urgency about everything.

17. Activities are well-planned.

18. People can wear wild looking clothing while on the job if they want.

19. New and different ideas are always being tried out.

20. The lighting is extremely good.

21. A lot of people seem to be just putting in time.

22. People take a personal interest in each other.

23. Supervisors tend to discourage criticisms from employees.

24. Employees are encouraged to make their own decisions.

25. Things rarely get "put off till tomorrow."

26. People cannot afford to relax.

27. Rules and regulations are somewhat vague and ambiguous.

28. People are expected to follow set rules in doing their work.

29. This place would be one of the first to try out a new idea.

30. Work space is awfully crowded.

31. People seem to take pride in the organization.

32. Employees rarely do things together after work.

33. Supervisors usually give full credit to ideas contributed by employees.

34. People can use their own initiative to do things.

35. This is a highly efficient, work-oriented place.

36. Nobody works too hard. 
37. The responsibilities of supervisors are clearly defined.

38. Supervisors keep a rather close watch on employees.

39. Variety and change are not particularly important.

40. This place has a stylish and modern appearance.

41. People put quite a lot of effort into what they do.

42. People are generally frank about how they feel.

43. Supervisors often criticize employees over minor things.

44. Supervisors encourage employees to rely on themselves when a problem arises.

45. Getting a lot of work done is important to people.

46. There is no time pressure.

47. The details of assigned jobs are generally explained to employees.

48. Rules and regulations are pretty well enforced.

49. The same methods have been used for quite a long time.

50. The place could stand some new interior decorations.

51. Few people ever volunteer.

52. Employees often eat lunch together.

53. Employees generally feel free to ask for a raise.

54. Employees generally do not try to be unique and different.

55. There's an emphasis on "work before play."

56. It is very hard to keep up with your work load.

57. Employees are often confused about exactly what they are supposed to do.

58. Supervisors are always checking on employees and supervise them very closely. 
59. New approaches to things are rarely tried.

60. The colors and decorations make the place warm and cheerful to work in.

61. It is quite a lively place.

62. Employees who differ greatly from the others in the organization don't get on well.

63. Supervisors expect far too much from employees.

64. Employees are encouraged to learn things even if they are not directly related to the job.

65. Employees work very hard.

66. You can take it easy and still get your work done.

67. Fringe benefits are fully explained to employees.

68. Supervisors do not often give in to employee pressure.

69. Things tend to stay just about the same.

70. It is rather drafty at times.

71. It's hard to get people to do any extra work.

72. Employees often talk to each other about their personal problems.

73. Employees discuss their personal problems with supervisors.

74. Employees function fairly independently of supervisors.

75. People seem to be quite inefficient.

76. There are always deadlines to be met.

77. Rules and policies are constantly changing.

78. Employees are expected to conform rather strictly to the rules and customs.

79. There is a fresh, novel atmosphere about the place.

80. The furniture is usually well-arranged.

81. The work is usually very interesting. 
82. Often people make trouble by talking behind others' backs.

83. Supervisors really stand up for their people.

84. Supervisors meet with employees regularly to discuss their future work goals.

85. There's a tendency for people to come to work late.

86. People often have to work overtime to get their work done.

87. Supervisors encourage employees to be neat and orderly.

88. If an employee comes in late, he can make it up by staying late.

89. Things always seem to be changing.

90. The rooms are well ventilated. 
APPENDIX D

Work Quality Index 
Work Quality Index

This questionnaire inquires about your level of satisfaction with 38 job-correlated factors. Please indicate how satisfied you are in your present job with each of these items by circling the appropriate number.

NOT

SATISFIED

SATISFIED

1. The work associated with your position allows you to make

contribution to:

.01 The hospital

.02 The profession

.03 Your own sense of achievement

$\begin{array}{lllllll}1 & 2 & 3 & 4 & 5 & 6 & 7 \\ 1 & 2 & 3 & 4 & 5 & 6 & 7 \\ 1 & 2 & 3 & 4 & 5 & 6 & 7\end{array}$

2. You receive adequate praise for work well done from:

.01 Your peers

.02 Hospital physicians

.03 Nursing administration

$\begin{array}{lllllll}1 & 2 & 3 & 4 & 5 & 6 & 7 \\ 1 & 2 & 3 & 4 & 5 & 6 & 7 \\ 1 & 2 & 3 & 4 & 5 & 6 & 7\end{array}$

3. The work associated with your position provides you with:

.01 Opportunity to use a full range of nursing skills

.02 A variety of clinical challenges

.03 The opportunity to be of gervice to others

$\begin{array}{lllllll}1 & 2 & 3 & 4 & 5 & 6 & 7 \\ 1 & 2 & 3 & 4 & 5 & 6 & 7 \\ 1 & 2 & 3 & 4 & 5 & 6 & 7\end{array}$

4. The nursing practice environment:
.01 Allows you to make autonomous nursing care decisions
.02 Allows you to be fully accountable for those decisions
.03 Encourages you to make adjustments in your nursing practice to suit patient needs
.04 Provides a stimulating intellectual environment
.05 Provides time to engage in research if ycu want
.06 Promotes a high level of clinical competence on your unit
.07 Allows opportunity to receive adequate respect from nurses on other units

$\begin{array}{lllllll}1 & 2 & 3 & 4 & 5 & 6 & 7 \\ 1 & 2 & 3 & 4 & 5 & 6 & 7 \\ 1 & 2 & 3 & 4 & 5 & 6 & 7 \\ 1 & 2 & 3 & 4 & 5 & 6 & 7 \\ 1 & 2 & 3 & 4 & 5 & 6 & 7 \\ 1 & 2 & 3 & 4 & 5 & 6 & 7 \\ 1 & 2 & 3 & 4 & 5 & 6 & 7\end{array}$


NOT

SATISFIED

SATISFIED

5. The hospital organizational

structure: policy making for nursing service

.02 Allows you to have a voice in overall hospital policy making

.03 Facilitates patient care

$\begin{array}{lllllll}1 & 2 & 3 & 4 & 5 & 6 & 7 \\ 1 & 2 & 3 & 4 & 5 & 6 & 7 \\ 1 & 2 & 3 & 4 & 5 & 6 & 7\end{array}$

6. You receive:

.01 Enough time to complete patient physical care tasks

.02 Enough time to complete indirect patient care tasks

.03 support for your work from nurses on other shifts

.04 Support from your peers for your nursing decisions

.05 Support from physicians for your nursing decisions

$\begin{array}{lllllll}1 & 2 & 3 & 4 & 5 & 6 & 7 \\ 1 & 2 & 3 & 4 & 5 & 6 & 7 \\ 1 & 2 & 3 & 4 & 5 & 6 & 7 \\ 1 & 2 & 3 & 4 & 5 & 6 & 7 \\ 1 & 2 & 3 & 4 & 5 & 6 & 7\end{array}$

7. Good working relationshipg exist between you and:

.01 Your supervisor

.02 Your peers

.03 Physicians

$\begin{array}{lllllll}1 & 2 & 3 & 4 & 5 & 6 & 7 \\ 1 & 2 & 3 & 4 & 5 & 6 & 7 \\ 1 & 2 & 3 & 4 & 5 & 6 & 7\end{array}$

8. Nursing service:

.01 Gives clear direction about advancement

.02 Provides adequate opportunities for advancement

.03 Decides advancements for nurses fairly

$\begin{array}{lllllll}1 & 2 & 3 & 4 & 5 & 6 & 7 \\ 1 & 2 & 3 & 4 & 5 & 6 & 7 \\ 1 & 2 & 3 & 4 & 5 & 6 & 7\end{array}$

9. Your job offers:

.01 Opportunity for professional growth

.02 Satisfactory salary

.03 Adequate funding for health care premiums

.04 Adequate additional financial benefits other than salary

.05 A satisfactory work hour pattern (eight hour, ten hour, and so forth)

.06 Adequate vacation

.07 Adequate sick leave

.08 Adequate inservice opportunities

$\begin{array}{lllllll}1 & 2 & 3 & 4 & 5 & 6 & 7 \\ 1 & 2 & 3 & 4 & 5 & 6 & 7 \\ 1 & 2 & 3 & 4 & 5 & 6 & 7 \\ 1 & 2 & 3 & 4 & 5 & 6 & 7 \\ 1 & 2 & 3 & 4 & 5 & 6 & 7 \\ 1 & 2 & 3 & 4 & 5 & 6 & 7 \\ 1 & 2 & 3 & 4 & 5 & 6 & 7 \\ 1 & 2 & 3 & 4 & 5 & 6 & 7\end{array}$


APPENDIX E

Permission Letter 
Q. Jacobs

SAN JOSE

A campus of The California State University STATE UNIVESTY

57

College of Applied Sciences and Arts - School of Nursing

One Washington Square • San José, California 95192-0057 • 408/924-3130 • Fax 408/924-3135

July 10, 1995

Marilyn Peddicord Whitley, PhD., RN

Associate Dean

Loyola University of Chicago

Dear Dr. Whitley:

I am a graduate student at San Jose State University School of Nursing, and in the process of completing my thesis. I am seeking permission to reproduce the Work Quality Index. I would also appreciate it if you could send me a copy of the complete questionnaire, and give me any information which you think is necessary.

The purpose of this study is to determine if there is a relationship between the work environment and job satisfaction of nurses. I will be collecting my data in October, 1995.

Your prompt response is greatly appreciated. I will provide you the results of the study upon request. Thank you very much for your consideration.

Should you need to get in touch with me, I may be reached at (408) 270-2977 (collect). Thank you.

$$
8-32-45
$$

Sincerely,
Cayabyab

Cecilia A. Cayabyab 2836 Croft Drive San Jose, CA, 95148

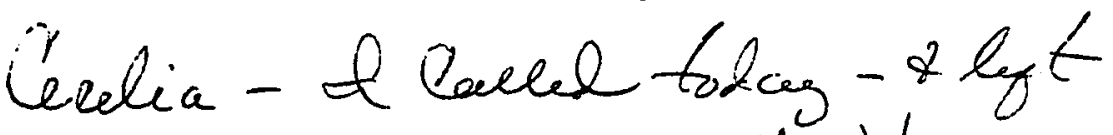
$m_{y}$ \# a mex - y eu have migernussion to usectwew the entire trial is displayed in th er 4-9\$ Journal article-kiony groper an very in

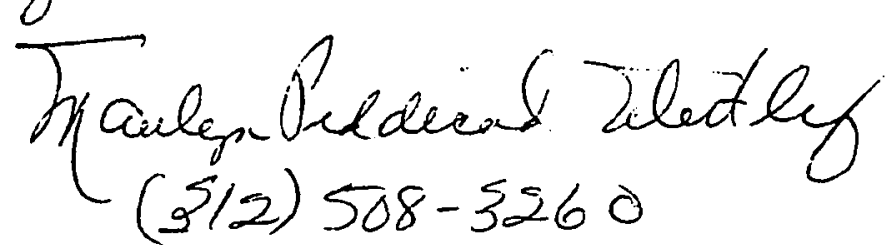

